\title{
Working Pasteur's Quadrant: Harnessing Science and Action for Community Change
}

\author{
Richard H. Price ${ }^{1,3}$ and Teresa Behrens ${ }^{2}$
}

\begin{abstract}
Community psychology in general and the field of prevention in particular has unquestioningly accepted the assumption that the research process should proceed in a linear fashion from a search for basic knowledge to application in the community context. This ignores the compelling insight offered by Stokes (1997) that the drive for new knowledge and the pursuit of application can be combined in a single effort. If research in community psychology pursues the drive for application without an equal commitment to the development of knowledge about underlying community processes of social cooperation and change, it will become a field less capable of innovative and enduring contributions to community well-being and effectiveness. Opportunities abound in community psychology for the simultaneous pursuit of new knowledge and more effective practice. We offer the example of a community leadership development program to promote collective efficacy as a case in point.
\end{abstract}

KEY WORDS: science; community; innovation.

Science is skeptical. Community action is idealistic. One of the most fundamental tensions in community psychology and in the Society for Community Research and Action is the tension between the cautious and skeptical demands of science and the imperatives of community action. We need to keep this tension alive in the field rather than abandoning either goal in favor of the other. We need to nurture the drive for fundamental new understanding of social and community processes at the same time that we engage in action for community development and change.

The making of a scientific paradigm. A remarkable and poorly understood fact is that the tension between "basic" and "applied" research has in some sense been manufactured in the making of the scientific paradigm that has dominated our thinking for

\footnotetext{
${ }^{1}$ University of Michigan, Ann Arbor, Michigan.

${ }^{2}$ Director of Evaluations, W. K. Kellogg Foundation, Battle Creek, Michigan.

${ }^{3}$ To whom correspondence should be addressed at 3334 ISR, Box 1248, University of Michigan, Ann Arbor, Michigan 48106-1248; e-mail: ricprice@umich.edu.
}

the last half-century (Stokes, 1997). A brief excursion into the history of science is needed to make this point clear. The end of WW II represented a watershed in science policy. In 1944, Franklin Roosevelt concerned about the future of science in the United States, asked Vannevar Bush in the Office of Scientific Research and Development to write a policy document to define the role of science in peacetime. In response, Bush wrote Science-The Endless Frontier (Bush, 1990) in which he argued that basic research should be performed "without the thought of practical ends," and he asserted that basic research would be the "pacemaker of technological change." The idea Bush put forward in The Endless Frontier was uncritically accepted for decades. The basic argument is that disinterested basic research is the fundamental and only path to later technological innovation and useful applied knowledge. Until recently, almost all engineering and most social science research and development paradigms reflected this idea.

Most paradigms offered to help structure the field of prevention research still do reflect this basic-to-applied assumption. This is the point made by Wandersman (2003). For example, Price (1987) 
described the prevention research cycle as a set of successive stages that moved in a linear fashion from basic problem analysis, to intervention design, then to field trials to test the effectiveness of the intervention, and finally, for those interventions that succeeded in each of the previous stages, to widespread dissemination. This paradigm suggests a linear movement from basic research to application, and ultimately to dissemination of some new social innovation. A more recent statement of this same idea is expressed in the Institute of Medicine report on prevention research in mental health, Reducing Risks for Mental Disorders (Mrazek \& Haggerty, 1994).

But in his path breaking book, Pasteur's Quadrant: Basic Science and Technological Innovation, Stokes (1997) points out that this dichotomy between basic and applied research and linear thinking about research and action is fundamentally mistaken. Instead, Stokes argues that the motive for fundamental understanding and the drive for application are not separate or in opposition to each other. Instead, these two motives for research can be combined in various ways. For example, Stokes argues that in his initial search for the structure of the atom, Neils Bohr was concerned entirely with fundamental understanding and not at all with considerations of application and use. On the other end of the spectrum, Stokes describes the work of Thomas Edison as being completely uninterested in fundamental understanding, and entirely motivated by considerations of application.

These are extreme examples of the pursuit of only a single one of the two motives of understanding or application. Can they be successfully combined? Stokes also offers us examples of scientists in history who successfully combined the drive for fundamental understanding with a desire for application. Louis Pasteur was the prototypical scientist who uncovered fundamental understanding about the nature of disease while doing applied research on the preservation of cheeses, beer, and milk! Pasteur never considered himself to be a basic researcher. Instead he carried with him into his applied projects the desire to solve a vexing puzzle and so was able to use what he observed in practical projects to assemble the jigsaw of the microbiological genesis of infectious disease.

The question for community psychology is which role model do we wish to emulate? Is it Edison, who spawned a number of influential inventions, but added also almost nothing to fundamental understanding about the physics of electricity? Is it Bohr, who was largely indifferent to the practical implications of his

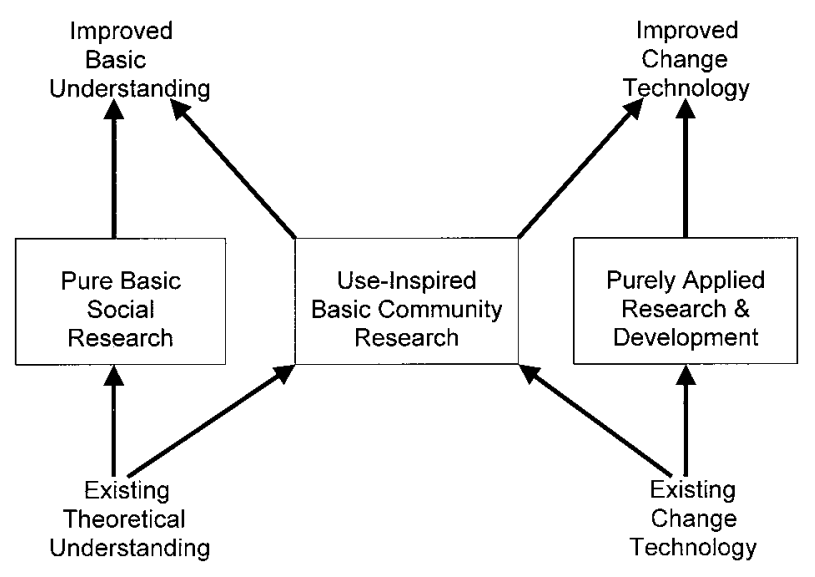

Fig. 1. Use inspired basic research for community psychology (Adapted from Stokes, 1997).

research, but who added greatly to our understanding of the fundamental understanding of matter? Or is it Pasteur who undertook practical projects with both the goal of improved application and improved understanding?

Figure 1 offers a revised paradigm for community research and action that deserves serious consideration. In this paradigm, several different paths are evident. First, like Bohr, our existing understanding could be pursued through research primarily motivated for new understanding. This is the path shown on the left side of Fig. 1 moving from bottom to top. A second pathway from existing applications to new ones suggests that existing technologies can be improved by engaging in purely applied research devoid of an interest in theory as Edison did. This is the path on the right of Fig. 1 from bottom to top. But Fig. 1 also suggests that we can engage in use inspired basic research in communities, drawing on both existing technology and existing theory in ways that expands both our theoretical understanding and our technical capability. Can we identify an example of use-inspired basic research in our own field concerned with both theoretical understanding and community change?

\section{WORKING PASTEUR'S QUADRANT TO STRENGTHEN COMMUNITY LEADERSHIP}

We offer an example where community research and action can be combined in ways suggested by Stokes (1997) formulation of "use inspired basic research." The Kellogg Leadership for Community Change (KLCC) initiative [http://www.wkkf.org/ Programming/Overview.aspx?CID=276] offers an 
example where both pursuit of new knowledge and efforts at community change are possible. The KLCC initiative is aimed at creating and strengthening collaborative leadership in communities by enhancing the leadership skills of a cadre of community leaders who will mobilize public will around issues of teaching and learning in their communities. The initiative represents a novel approach to leadershiptrying to develop a group of leaders in their communities, rather than selecting individuals for leadership development. The participants are people who have typically not been part of the leadership structures in their communities, and represent the diversity in age, economic status, education, and ethnicity of the communities.

In each community, the participants will engage in a variety of leadership development activities to enhance their ability to address a local issue related to teaching and learning; the group chooses which problem to tackle. The problems range widely and include examples such as (1) addressing performance gaps between students in different ethnic communities, (2) incorporating traditional tribal knowledge, language, and cultural history into local education programs, and (3) developing strategies for life-long learning in rural communities through postsecondary education programs. The initiative is intended to train leaders in collaborative and inclusive decision making, creating trusting relationships, mobilizing people for collective action, all in the interest of institutional and community capacity building. Community mobilization in each of these communities will involve the engagement of local community-based organizations, schools, and local community leaders in an increasingly interconnected web of social relationships to build social relationships, and in evaluating alternative community innovations that can address local problems of concern.

The KLCC initiative is an action-oriented community project where both basic inquiry and community action might be fruitfully combined. By working in Pasteur's quadrant, we can both contribute to the development of the KLCC approach to group leadership development and to the knowledge base on the underlying community processes, such as the role of collective efficacy in community change.

The role of collective efficacy. In community psychology there is considerable interest in a deeper understanding of how individuals and groups in communities form beliefs about their ability to successfully meet challenges confronting them. One stream of research and theory on the psychology of coping with challenge has been stimulated by Bandura (1995) who defined self-efficacy as people's beliefs in their capability to perform in ways that give them control over events that affect their lives. The underlying premise is that unless people can believe they can produce results by their actions, they have little incentive to act. Hundreds of studies have demonstrated that strong beliefs in self-efficacy predict success at a wide range of tasks (Bandura, 1995). More recently, considerable interest has developed in an idea more congenial to community psychologists, the idea of collective efficacy, that is, people's shared beliefs in their collective ability meet a challenge and produce desired outcomes for the group (Morenoff, Sampson, \& Raudenbush, 2001; Sampson, Morenoff, \& Earls, 1999; Sampson, Raudenbush, \& Earls, 1997). Beliefs in collective efficacy influence how well people in communities engage in collective action and use their resources to meet a community challenge. Collective efficacy also predicts people's willingness to persist and their staying power when initial efforts fail.

A series of recent studies of 9,000 residents in 343 neighborhoods in Chicago, Illinois (Morenoff et al., 2001; Sampson et al., 1997, 1999) has explored the degree to which neighborhoods varying in collective efficacy also vary in other critical community outcomes such as concern and caring for children and delinquency. In a careful and comprehensive study of neighborhood concern about crime and delinquency in children and youth, residents were asked about (1) the likelihood that their neighbors could be counted on in various ways, (2) willingness to help neighbors, (3) perception that the neighborhood is close-knit, (4) that neighbors can be trusted, and (5) that neighbors share the same values and can get along with each other.

While these studies continue, the most important finding of these studies of collective efficacy in neighborhoods and communities was that variation between neighborhoods in outcomes important to children was attributable to perceptions of community and collective efficacy over and above the influence of socioeconomic and other demographic characteristics of neighborhood residents. This line of research suggests that collective efficacy is a critical ingredient in the capacity to make improvements in the quality of community life. But working in Pasteur's Quadrant we would also be moved to ask, what are the determinants of collective efficacy itself and, how might community leaders like those participating in the KLCC initiative help create an enhanced sense of collective efficacy in their own communities? 
Community leaders building social capital: Relationships, norms and networks. What can community leaders do to build community assets for effective community change? We argue that one of the most important functions of community leaders is to build social capital in arenas where there is consensus for problem solving. One of the most compelling ways of thinking about community assets has been described by Coleman (1988) as the idea of social capital. Unlike physical capital such as equipment or technology, or human capital reflected in individual knowledge and skills, social capital is reflected in the nature and quality of relationships between individuals in a community setting.

Coleman (1988) suggests that three forms of social capital are important to help individuals meet their needs and pursue their goals: (1) trusting relationships, (2) social networks, and (3) shared community norms and sanctions. According to the social capital perspective, a community is effective at pursuing a particular goal if they have developed each of these three forms of social capital. There is evidence that neighborhoods and educational communities that have high levels of social capital are more likely to achieve their goals (Coleman, 1988) and Putnam (2000) argues that social capital supports the functioning of democratic institutions. A hypothesis for working in Pasteur's Quadrant might then be that, as KLCC community leaders create social capital among themselves and others they will have created the necessary conditions for collective efficacy. In short, our hypothesis is that new leaders who can foster a sense of collective efficacy by both engaging in the existing social networks and creating new ones will be more successful in creating community change. The evaluation of this effort will include pre- and postsurveys designed to assess the social capital within these six communities, as well as in-depth qualitative assessment of the individual and community development processes. We believe that this approach will inform not only this new approach to community leadership development, but also our understanding of the basic processes involved.

\section{A MATTER OF VALUES AND A WAY OF LOOKING AT THE WORLD}

We have argued that neither a disinterested pursuit of understanding for its own sake nor pursuit of action for its own sake is the preferred path for community psychologists. Instead, we advocate work in a more challenging arena, Pasteur's Quadrant, where no action step is contemplated without questioning about its theoretical significance and no speculation about underlying processes occurs without asking about its action implications. This is difficult work, and may not be to everyone's taste. The social and behavioral sciences generally tend to divide themselves into separate camps specializing in action and change on the one hand, or reflection and theory development on the other. In engineering disciplines, new organizational structures that promote working in this quadrant have been created such as the National Science Foundation's Industry-University Cooperative Research Centers. Perhaps social and behavioral scientists could benefit from new ways of organizing our work that support this duality.

We suggest resistance to an easy division of labor. Instead, we believe action projects like the example of the KLCC initiative on community leadership can be pursued both to improve our understanding of how leaders go about increasing collective efficacy to stimulate lasting community change, while at the same time, supporting those leaders in their efforts. In the end working Pasteur's Quadrant is not a technical matter of the choice of methodology or whether we choose to call our enterprise a "science" or not. It is instead about whether we can simultaneously hold the core values of an unflinching and skeptical pursuit of new knowledge while at the same time advocating for the quality of community life

\section{REFERENCES}

Bandura, A. (1995). Exercise of personal control and collective efficacy in changing societies. Cambridge, UK: Cambridge University Press.

Bush, V. (1990). Science-The Endless Frontier: A Report to the President on a Program of Postwar Scientific Research. Washington, DC: National Science Foundation, Reprinted, 1990.

Coleman, J. (1988). Social capital in the creation of human capital. American Journal of Sociology, 94, 95-120.

Goddard, R. (2002). A theoretical and empirical analysis of the measurement of collective efficacy: The development of a short form. Educational and Psychological Measurement, 62 (1), 97110 .

Heller, K., Price, R. H., Reinharz, S., Riger, S., \& Wandersman, A. (1984). Psychology and community change. Homewood, IL: The Dorsey Press.

Mayer, J. P., \& Davidson, W. S., II. (2000). Dissemination of innovation as social change. In J. Rappaport \& E. Seidman (Eds.), Handbook of community psychology (pp. 421-438). New York: Kluwer Academic/Plenum Publishers.

Morenoff, J. D., Sampson, R. J., \& Raudenbush, S. W. (2001). Neighborhood inequality, collective efficacy, and the spatial dynamics of urban violence. Criminology, 39 (3), 517-559. 
Mrazek, P. J., \& Haggerty, R. J. (1994). Reducing risks for mental disorders: Frontiers for preventive intervention research. Washington, DC: National Academy Press.

Price, R. H. (1987). Linking intervention research and risk factor research. In A. Steinberg \& M. M. Silverman (Eds.), Preventing mental disorders: $A$ research perspective (DHHS Publication No. ADM 87-1492, pp. 48-56). Washington, DC: U.S. Government Printing Office.

Price, R. H. (in press). Understanding and improving the mental health of populations. In J. S. House, R. L. Kahn, F. T. Juster, H. Schuman, \& E. Singer (Eds.), A telescope on society: Survey research and social science in the twentieth and twenty-first centuries. Ann Arbor, MI: University of Michigan Press.
Putnam, R. D. (2000). Bowling alone: Collapse and revival of the American community. New York: Simon \& Schuster.

Sampson, R. J., Morenoff, J. D., \& Earls, F. (1999). Beyond social capital: Spatial dynamics of collective efficacy for children. American Sociological Review, 64 (5), 633-660.

Sampson, R. J., Raudenbush, S. W., \& Earls, F. (1997). Neighborhoods and violent crime: A multilevel study of collective efficacy. Science, 277 (5328), 918-924.

Stokes, D. (1997). Pasteur's Quadrant: Basic science and technological innovation. Washington, DC: Brookings Institution Press.

Wandersman, A. (2003). Community Science: Bridging the gap between science and practice with community-centered models. American Journal of Community Psychology, 31, (3/4), 227242. 